Goldschmidt 2021 Abstract

https://doi.org/10.7185/gold2021.4856

\title{
Assessing Human Imprints on Trace Metal Loads in the Great Lakes
}

\section{JACOB PINTER, COLTON BENTLEY, TASSIANE JUNQUEIRA AND BAS VRIENS}

\author{
Queen's University
}

Presenting Author: 15fjp1@queensu.ca

Trace metals are increasingly used in industry and society and their occurrence in anthropogenic waste streams is growing correspondingly. Yet, trace metal loads in wastewater and urban runoff, and their potential environmental impacts on freshwater systems, remain poorly quantified beyond local contaminated sites. The Laurentian Great Lakes basin ( $>60$ million people) provides a globally unique setting to investigate the human imprints on large-scale trace metal cycling because it is extensively monitored and consists of serially connected subbasins that facilitate environmental system analyses at various scales.

We established baseline estimates of natural trace metal loads in the Great Lakes by aggregating hydrometric and water quality data in long-term mass-balance models and dynamic transport simulations. These models were informed by $>100,000$ hydrometric and $>5,000$ water quality measurements collected across the Great Lakes between 1980-2020 and were calibrated to existing long-term water level and water quality records. All incorporated data stems from Canadian and US federal and provincial and state monitoring programs, including publicly available datasets from NOAA, EPA, ECCC, IADN, Ontario, Michigan, and select municipalities and local conservation authorities. For conservative elements $(\mathrm{Cl}, \mathrm{Na})$, mass-balance could be achieved at $>94 \%$ and long-term trends could be accurately reproduced. However, highly variable source-sink behavior was observed for biogeochemically reactive elements (e.g., $\mathrm{Cu}, \mathrm{Zn}, \mathrm{Pb}$ ) across the upper and lower Great Lakes, with select tributaries strongly affecting lake-wide trace metal dynamics.

We also collected and analyzed wastewater effluent and sludge samples from $>40$ US and Canadian wastewater treatment facilities (WWTF) and assessed discharge loads for $>20$ trace metals. Using wastewater as a proxy for human activity, we compared average wastewater-effluent loads with large-scale natural loads trough the Great Lakes basin, allowing us to compare different trace metals and individual lakes and tributaries by their apparent human fingerprint. Our results show anomalously high loading rates for select WWTF-derived trace metals in multiple tributary systems, which we quantitatively contextualize by geospatial analysis of sewershed attributes. We are currently expanding our models with new ultra-trace level analyses of freshwater samples from cruise expeditions and tributary surveillance, as well as analysis of WWTF samples and precipitation and sediment records. 